Бахматов П. В., Муравьев В. И., Физулаков Р. А.

P. V. Bakhmatov, V. I. Muravyev, R. A. Fizulakov

ОСОБЕННОСТИ РАЗРУШЕНИЯ ЭЛЕМЕНТОВ СВАРНЫХ ТИТАНОВЫХ КОНСТРУКЦИЙ (РЕБРИСТЫХ ПАНЕЛЕЙ) В УСЛОВИЯХ ВИБРАЦИОННЫХ НАГРУЗОК

\title{
FEATURES OF WELDED TITANIUM STRUCTURE ELEMENT DESTRUCTION (RIBBED PANELS) UNDER VIBRATION LOADS
}

Бахматов Павел Вячеславович - кандидат технических наук, доцент, зав. кафедрой «Машиностроение и металлургия» Комсомольского-на-Амуре государственного технического университета (Россия, Комсомольск-на-Амуре); 681013, г. Комсомольск-на-Амуре, ул. Ленина, 27. E-mail: mim@knastu.ru.

Mr. Pavel V. Bakhmatov - PhD in Engineering, Associate Professor, Head of the department «Mechanical engineering and metallurgy», Komsomolsk-on-Amur Technical University (Russia, Komsomolsk-on-Amur); 681013, Komsomolsk-on-Amur, 27 Lenin str. E-mail: mim@knastu.ru.

Муравьев Василий Илларионович - доктор технических наук, профессор, профессор кафедры «Машиностроение и металлургия» Комсомольского-на-Амуре государственного технического университета (Россия, Комсомольск-на-Амуре); 681013, г. Комсомольск-на-Амуре, ул. Ленина, 27. E-mail: mim@knastu.ru.

Mr. Vasiliy I. Muravyev - Doctor of Engineering, professor, Mechanical engineering and metallurgy Department, Komsomolsk-on-Amur Technical University (Russia, Komsomolsk-on-Amur); 681013, Komsomolsk-on-Amur, 27 Lenin str. E-mail: mim@knastu.ru.

Физулаков Роман Анатольевич - кандидат технических наук, доцент, доцент кафедры «Материаловедение и технология новых материалов» Комсомольского-на-Амуре государственного технического университета (Россия, Комсомольск-на-Амуре); 681013, г. Комсомольск-на-Амуре, ул. Ленина, 27. E-mail kmtnm@knastu.ru

Mr. Roman A. Fizulakov - PhD in Engineering., Associate Professor, Materials and New Materials Technology Department, Komsomolsk-on-Amur Technical University (Russia, Komsomolsk-on-Amur); 681013, Komsomolskon-Amur, 27 Lenin str. E-mail: kmtnm@knastu.ru

Аннотация. В статье приведены данные по результатам экспериментальных исследований на вибрационную нагрузку сварных ребристых панелей из титанового сплава ВТ-20. Установлено, что в зонах крепления наблюдаются повышенные динамические знакопеременные напряжения, которые в сочетании с «жёстким» креплением образца создают благоприятные условия для зарождения и развития усталостных трещин, a концентраторы напряжений значительно сокращают время до образования очага разрушения. Исключение в этих зонах поверхностных дефектов не оказывает влияния на характер и кинетику разрушения. Конструкции из титановых сплавов, изготовленные при применении газолазерного раскроя заготовок по оптимальным режимам в среде технического азота и последующей термической обработке по вибронадежности, не уступают конструкциям, сделанным по традиционной технологии.

Summary. The article presents data on the experimental studies results of welded ribbed panel vibration load of the BT-20 titanium alloy. It was established that in the areas of attachment, there is elevated dynamic alternating stress, which in combination with the "hard" of the sample holder creates favorable conditions for the emergence and development of fatigue cracks, and stress concentrators greatly reduce the time before the formation of the hearth destruction. An exception in these zones of superficial defects do not affect the nature and kinetics of destruction Construction of titanium alloys made in the application of gas-laser cutting blanks for optimal regimes in the technical environment of nitrogen and subsequent heat treatment on vibration reliability is not inferior to design, made by traditional technology.

Ключевые слова: циклическая прочность, динамические нагрузки, титановые ребристые сварные конструкции, режимы сварки, разрушения.

Key words: cyclic strength, dynamic loads, titanium ribbed welded structures, welding modes, destruction. 
Бахматов П. В., Муравьев В. И., Физулаков Р. А.

ОСОБЕННОСТИ РАЗРУШЕНИЯ ЭЛЕМЕНТОВ СВАРНЫХ ТИТАНОВЫХ КОНСТРУКЦИЙ (РЕБРИСТЫХ ПАНЕЛЕЙ) В УСЛОВИЯХ ВИБРАЦИОННЫХ НАГРУЗОК

\section{УДК 621.7.092}

Как известно, реальные механические конструкции (в особенности конструкции авиационной и ракетной техники) часто эксплуатируются в условиях значительных вибрационных нагрузок. В связи с указанным характером эксплуатации при проектировании подобных аппаратов возникает необходимость учёта не только значений, реально действующих динамических нагрузок, но и их распределения по объёму конструкции, а при выборе конструкционного материала на первый план выходят не столько статические характеристики материала, сколько эксплуатационные характеристики, определяющие его долговечность.

В ходе циклического нагружения при относительно низких нагрузках в материале происходят микродеформации, приводящие к наклёпу в соответствующих областях, в результате чего образуются постепенно развивающиеся микротрещины, которые уменьшают «рабочую» область сечения конструкции и в дальнейшем приводят к мгновенному разрушению материала. Очевидно, что наличие дефектов (особенно поверхностных) в эксплуатируемых конструкциях оказывает значительное влияние как на процесс усталостного разрушения, так и на соответствующие усталостные характеристики материала.

Весь комплекс технологических операций изготовления сварных титановых ребристых панелей безусловно оказывает влияние на поверхностную дефектную структуру конструкции и, следовательно, на её эксплуатационные характеристики. В связи с чем исследование разрушения реальных авиационных ребристых конструкций в условиях вибрационных нагрузок представляет не только научный интерес, но и практическую значимость.

С этой целью были разработаны и изготовлены натурные образцы из сплава ВТ20 толщиной 1,2 мм (см. рис. 1). Конструкция опытного образца в миниатюре представляла собой характерный участок силовой панели летательного аппарата [1]. Образцы состоят из четырех сварных заготовок и двух стрингеров высотой 20 и 10 мм, раскроенных на лазерной установке BYSTRONIC-BYSTAR-3015 с использованием технического азота класса 4,5. Общий размер сварного образца $300 \times 600$ мм.

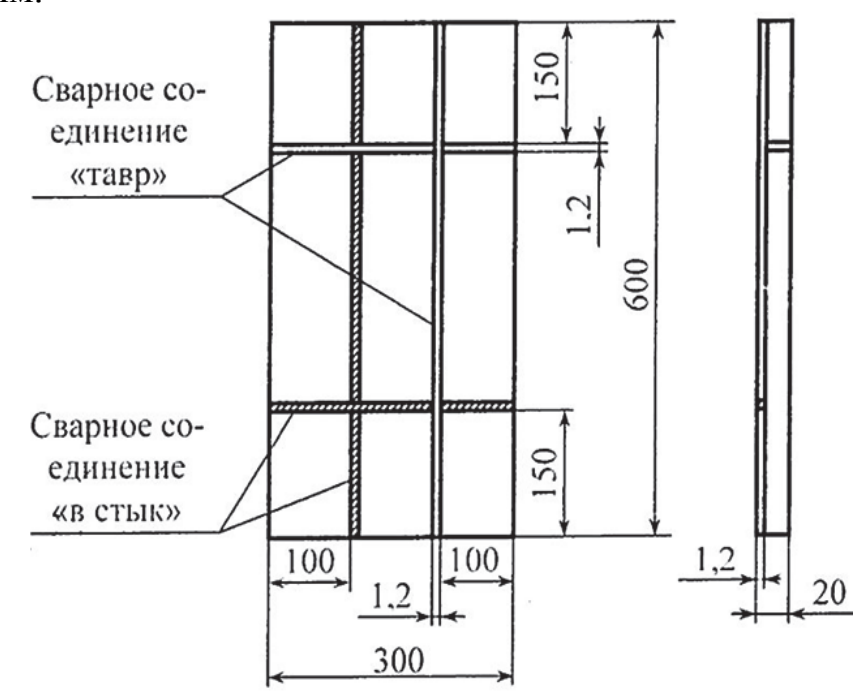

Рис. 1. Эскиз экспериментальных образцов

Сварку ААрДЭС проводили сквозным проплавом по инструкции НИАТ ПИ-1.4.898-88. Категория сварных соединений ААрДЭС сквозным проплавом и стыковых - 1. Рентген-контроль сварных соединений ААрДЭС.

Использовались сварные стыковые и тавровые соединения (сварка стрингеров) для более полного выяснения влияния газолазерной резки (ГЛР) на свойства сварного шва (СШ). С этой же целью СШ делали как в продольном, так и в поперечном направлении относительно прокатки. Кромки готовой к испытанию конструкции имели как фрезерованную, так и образованную ГЛР поверхность. 


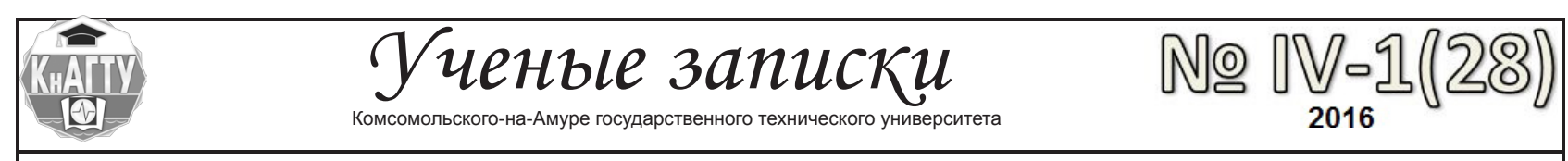

Отжиг готовой детали для снятия остаточных напряжений на кромках, вызванных ГЛР и последующей сваркой, проводили в вакуумной печи УВН-1545 при $650{ }^{\circ} \mathrm{C}, 1$ ч.

Испытания проводились на вибраторе V954MKII. Образец крепился к столу виброустановки с помощью втулок Ø20 мм и высотой 40 мм. При испытаниях для увеличения динамических нагрузок применялся груз массой 250 г. Места установки грузов и схемы крепления образца приведены на рис. 2, 3.

a)

б)
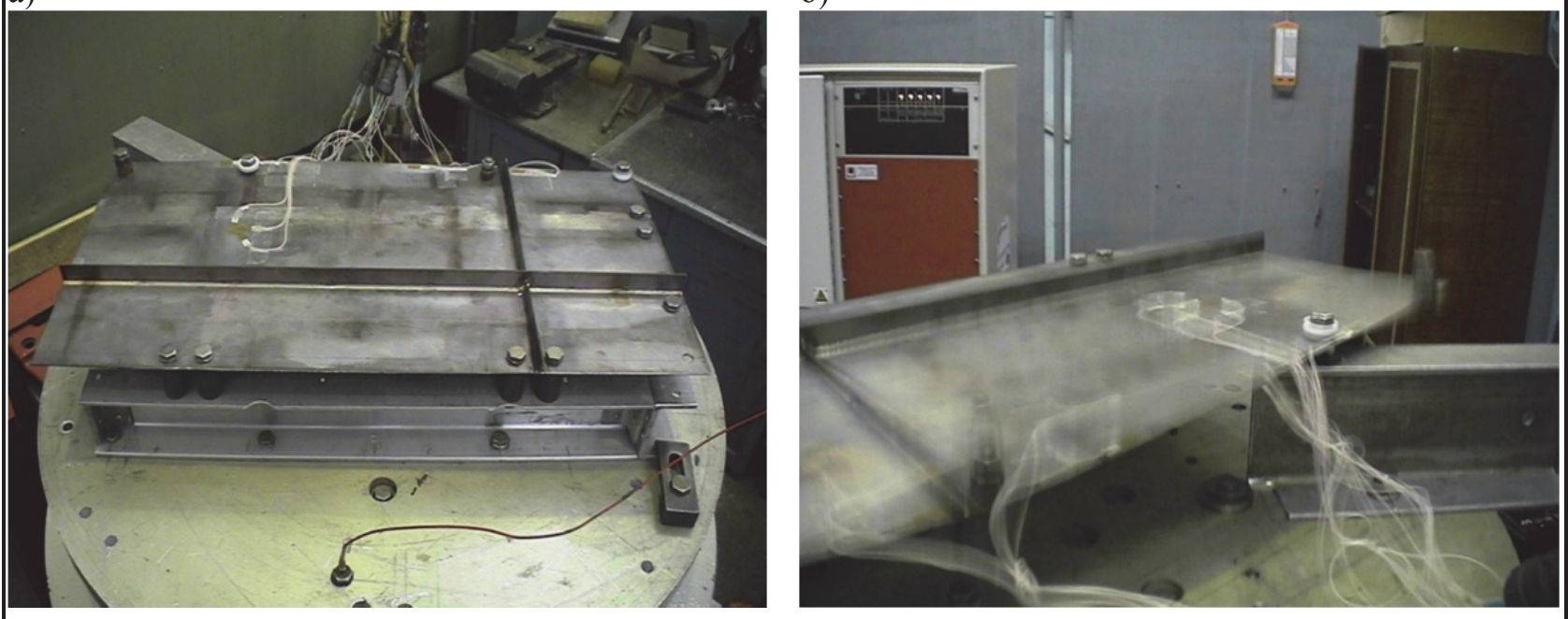

Рис. 2. Фото образца, закрепленного на вибростенде (а) и в процессе виброиспытания (б)

Для выбранных образцов и схем их крепления определялись резонансные частоты в диапазоне (10...400) Гц, а также проводились испытания на вибропрочность (испытания в условиях вибрационных нагрузок при резонансных частотах до разрушения конструкции). После разрушения конструкции проводились визуально-оптические, металлографические, рентгенографические и электронно-микроскопические исследования зон разрушения. Кроме того, в ходе испытаний регистрировались механические напряжения в характерных точках конструкции, схемы размещения тензодатчиков приведены на рис. 3. Результаты испытаний представлены в табл. 1.

a)

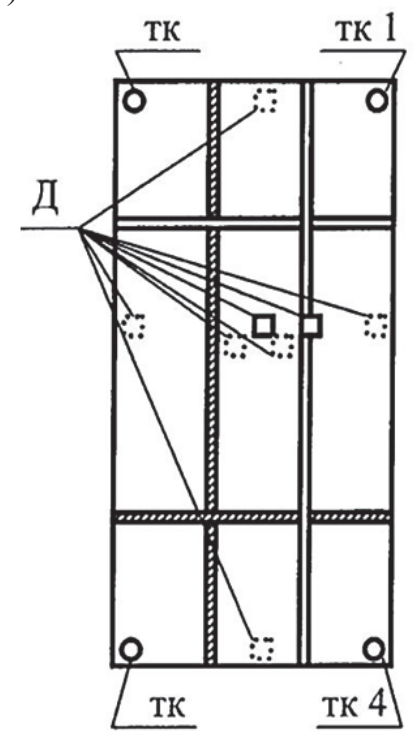

б)

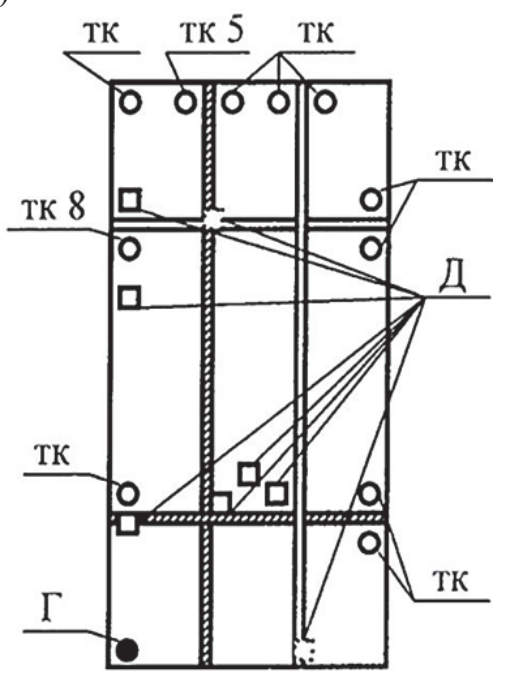

Рис. 3. Схемы испытания образцов

(Д - тензодатчик, тк - точка крепления образца, Г- груз 250 и 420 г) 
Бахматов П. В., Муравьев В. И., Физулаков Р. А.

ОСОБЕННОСТИ РАЗРУШЕНИЯ ЭЛЕМЕНТОВ СВАРНЫХ ТИТАНОВЫХ КОНСТРУКЦИЙ (РЕБРИСТЫХ ПАНЕЛЕЙ) В УСЛОВИЯХ ВИБРАЦИОННЫХ НАГРУЗОК

Таблица 1

Режимы испытаний образцов

\begin{tabular}{|c|c|c|c|}
\hline \multirow{2}{*}{ Схема крепления } & \multicolumn{3}{|c|}{ Режим испытания } \\
\cline { 2 - 4 } & Частота, Гц & Виброперегрузка, $\mathrm{g}$ & Время испытания, ч \\
\hline \multirow{2}{*}{ Рис. 3, $a$} & 49 & 5 & 13 \\
\cline { 2 - 4 } & 32 & 7 & 1,5 \\
\hline \multirow{2}{*}{ Рис. 3, $\sigma$} & 38 & 6 & 0,5 \\
\cline { 2 - 4 } & 24 & 7 & 13 \\
\hline
\end{tabular}

Видно, что схема крепления и частота вибрации оказывают значительное влияние на характер распределения нагрузки по объёму образца и, следовательно, на время зарождения и развития трещин. Максимальные напряжения возникают как в зонах повышенной жёсткости (зонах крепления образца, вблизи областей таврового соединения), так и в зонах максимальных деформаций.

В результате испытаний разрушение образцов произошло в зонах их крепления, при этом в образцах (см. рис. 4), закреплённых по схеме 1 (см. рис. 3, a), образование трещин произошло вблизи 1-й и 4-й точек крепления, а в образцах, закреплённых по схеме 2 (см. рис. 3, б), трещины появились вблизи 5-й и 8-й точек крепления.

a)

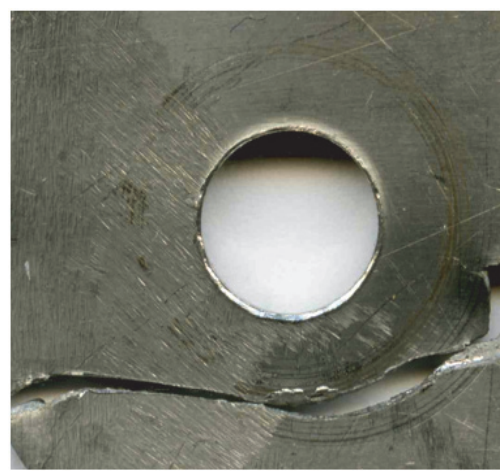

б)

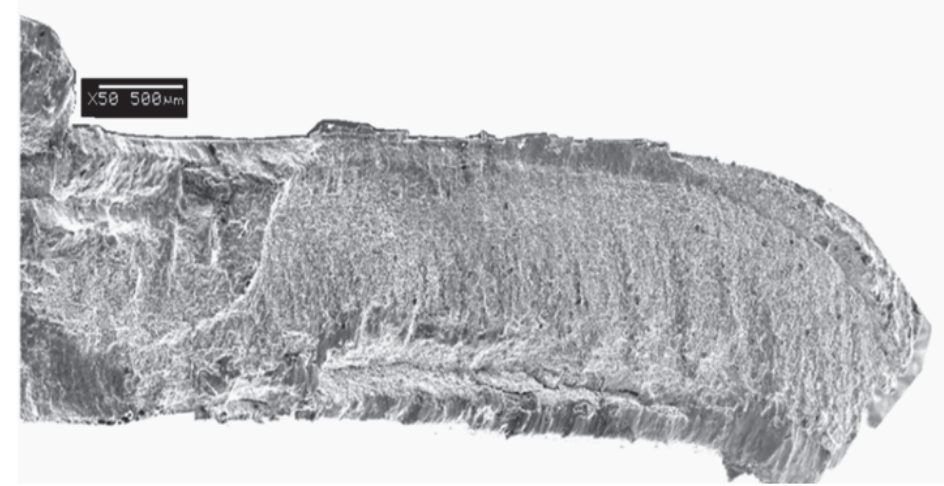

B)

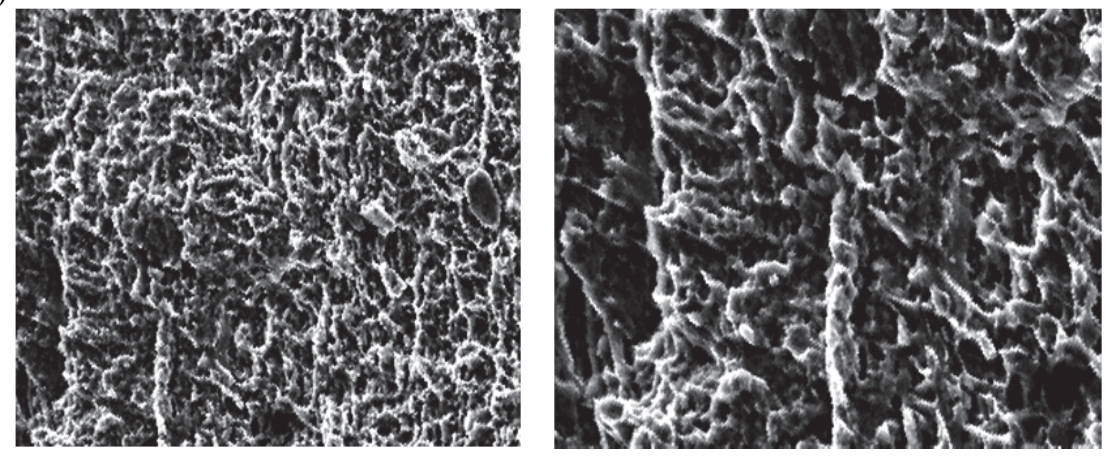

Рис. 4. Макроструктура зоны разрушения ТК8 и ТК5:

a - следы контакта шайбы и развитие трещины по линии контакта шайбы;

б - фрактограмма излома по месту разрушения (начало разрушения и смена направления разрушения); в - ячеистая структура излома и характерные ступеньки, остановки и развитие разрушения

Зарождение трещин происходило от местных поверхностных концентраторов напряжений (вмятины, риски, забоины и т.д.) на расстоянии порядка 2,5 мм от отверстий. Интересно, что более значительные концентраторы напряжений, расположенные на поверхности отверстий (заусенцы, 
микротрещины), а также концентраторы, расположенные на расстоянии порядка 10 мм от места зарождения трещины (следы от ударного клейма, вмятины от крепёжных шайб), не оказали влияния на место зарождения трещины и послужили лишь местами остановки развития трещины. Развитие трещин происходило в основном по касательной к окружности, проходящей через точки крепления образца.

Анализ места и характера разрушения свидетельствует о том, что у всех образцовимитаторов разрушение начинается в зоне максимальных напряжений: у мест жесткого крепления груза к образцу. Распространение разрушения происходит по большому кругу, точки крепления как бы ограничивают этот круг. Резонансная частота колебаний образца-имитатора к моменту остановки волны одного знака и появлению новой волны другого знака у зоны крепления, т.е. в этом месте происходит возвратно-поступательная смена знака напряжений при переходе «хлопуна» из выпуклого состояния в вогнутое, что вызывает максимум растягивающих напряжений. В точке крепления груза ТК8 (см. рис. 3) наблюдается кроме этого еще и максимум амплитуды колебаний (см. рис. 5).

a)

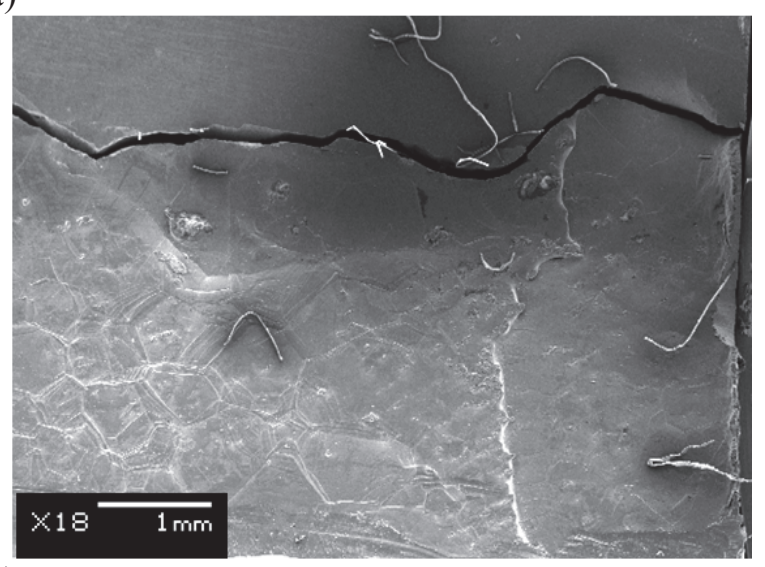

B)

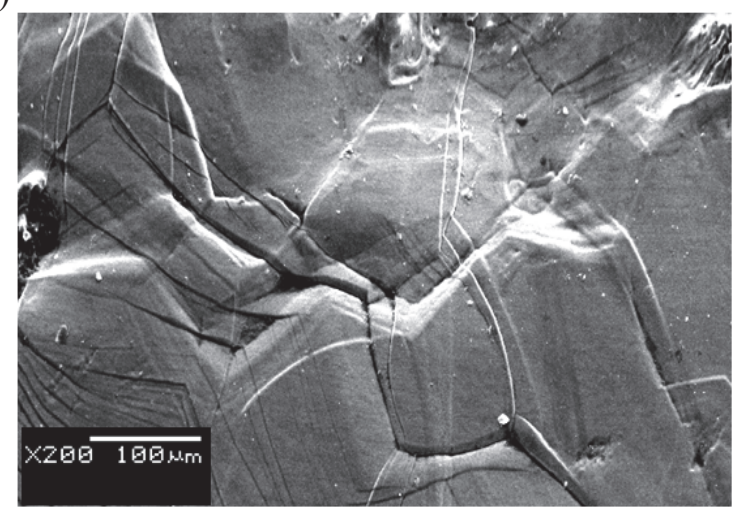

б)

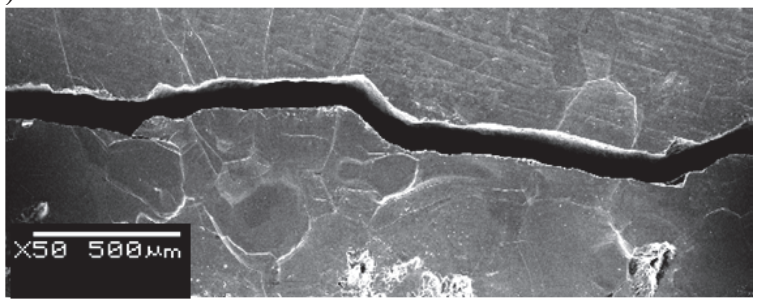

Г)

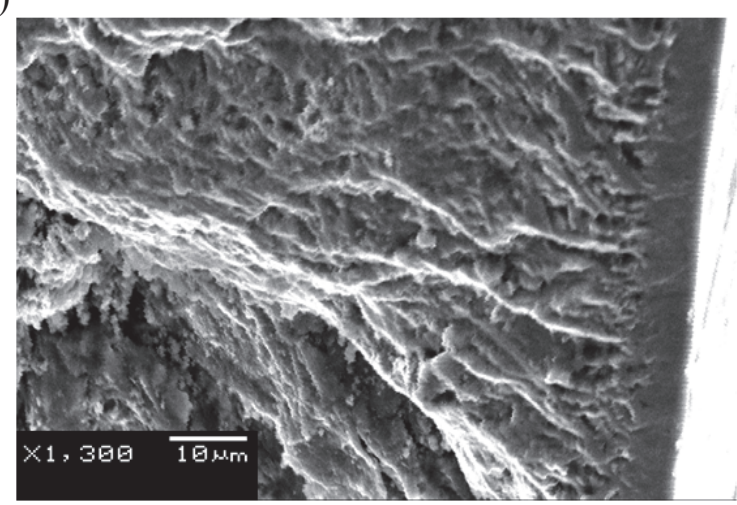

Рис. 5. Макроструктура зоны разрушения сварного шва в процессе виброиспытаний в точке крепления ТК8: а - начало разрушения от фрезерованной кромки

с распространением по радиусу галтели; б - разрушение как по границам зерна, так и по зерну транскристаллитное; в - двойникование в зерне и формирование микротрещин на стыке зерен; г - фрактограмма излома по месту разрушения: ступенчатый характер разрушения остановки и развитие разрушения

На всех образцах в точках крепления наблюдаются следы контакта шайбы с поверхностью образцов, но разрушение произошло только в ТК5 и ТК8 (см. рис. 3).

Подобное различие в образовании усталостных трещин можно объяснить исходя из следующего. В процессе виброиспытания, в различных точках образца-имитатора возникают области высокого уровня напряжений, близких к пределу текучести материала. По разному ведут себя эти 
Бахматов П. В., Муравьев В. И., Физулаков Р. А.

ОСОБЕННОСТИ РАЗРУШЕНИЯ ЭЛЕМЕНТОВ СВАРНЫХ ТИТАНОВЫХ КОНСТРУКЦИЙ (РЕБРИСТЫХ ПАНЕЛЕЙ) В УСЛОВИЯХ ВИБРАЦИОННЫХ НАГРУЗОК

«области» в зоне жесткого крепления и в любой другой точке образца-имитатора из-за того, что в первом случае происходит жесткая остановка волны вибрации по сравнению со свободным перемещением ее в любой другой точке. При приближении волны вибрации к точке крепления уровень напряжений может превысить предел текучести материала и привести к появлению необратимой повреждаемости (скольжению, двойникованию), которая при достижении некоторого критического уровня плотности дефектов приводит к возникновению первоначальной поверхности трещины или очагу разрушения. Этим можно объяснить и тот факт, что первоначальная трещина усталости возникает не в месте максимального вмятия шайбы в материал образца-имитатора (см. рис. 2), а на некотором расстоянии от этого места, и дальнейшее распространение трещины идет уже по другой траектории.

Как видно из данных рис. 4-5, отсутствие следов пластической деформации в зоне появления макро- и микротрещин, сдвиговые процессы и двойникование в зерне и формирование микротрещин на стыке зерен - все это свидетельствует об усталостном разрушении образцовимитаторов. Об этом свидетельствуют и результаты фрактографических исследований. Четко обнаруживаются зоны с фасеточным рельефом и смешанным фасеточным и ямочным рельефом, а также с зонами вытягивания на границе перехода от усталости к долому.

Таким образом, в зонах крепления образцов к вибростенду наблюдаются повышенные динамические знакопеременные напряжения, которые в сочетании с «жёстким» креплением образца создают благоприятные условия для зарождения и развития усталостных трещин. Присутствие в указанных зонах поверхностных дефектов и других концентраторов напряжений значительно сокращает время до образования очага разрушения.

Исключение в этих зонах поверхностных дефектов, вызванных, например, концентраторами напряжений, порами в металле сварного шва, крупным зерном в ЗТВ, грубой механической обработкой и др., не оказывает влияния на характер и кинетику разрушения.

Приведенные исследования показали, что конструкции из титановых сплавов, изготовленные при применении газолазерного раскроя заготовок по оптимальным режимам в среде технического азота и последующей термической обработке по вибронадежности, не уступают конструкциям, изготовленным по традиционной технологии.

Учитывая вышесказанное, при расчёте и разработке технологии изготовления конструкций, эксплуатируемых в условиях вибрационных нагрузок, приоритетное внимание заслуживает вопрос исследования распределения напряжений и обеспечения в зонах повышенных напряжений (особенно в зонах «жёстких» креплений) условий для надёжной и долговечной эксплуатации материала.

\section{Выводы:}

1. В процессе виброиспытаний в различных образцах-имитаторах возникают области высокого уровня напряжений, близких к пределу текучести материала, которые только в зоне жесткого крепления привели к появлению необратимой повреждаемости (скольжению, двойникованию), критическому уровню плотности дефектов и возникновению первоначальной поверхностной трещины в последующем к очагу разрушении.

2. Наличие высокого уровня напряжений, близкого к пределу текучести материала в точках, расположенных в зонах газолазерного раскроя кромок, сварки после газолазерного раскроя заготовок в процессе виброиспытаний к образованию очагов усталостного разрушения не привело.

3. Приведенные исследования показали, что конструкции из титановых сплавов, изготовленные при применении газолазерного раскроя заготовок по оптимальным режимам в среде технического азота и последующей термической обработке по вибронадежности, не уступают конструкциям, сделанным по традиционной технологии.

\section{ЛИТЕРАТУРА}

1. Испытания сварных натурных образцов сплава ВТ-20 на вибропрочность / В. И. Муравьев, Р. А. Физулаков, В.П. Иванов, Е. Н. Новиков // «Авиация и космонавтика - 2005»: материалы 4-й Междунар. конф.; Москва, 10-11 октября 2005 г. - М.: Московский авиационный институт, 2005. 